\title{
Foraging in a complex environment - semiochemicals support searching behaviour of the seven spot ladybird
}

\author{
JAN PETTERSSON ${ }^{1}$, Velemir NINKOVIC ${ }^{1}$, Robert GLINWOOD ${ }^{1}$, Michael A. BIRKETT ${ }^{2}$ and John A. PICKETT ${ }^{2}$ \\ ${ }^{1}$ Department of Entomology, Box 7044, SE-750 07, Uppsala, Sweden \\ ${ }^{2}$ Biological Chemistry Division, Rothamsted Research, Harpenden, Herts., AL5 2JQ, UK
}

Key words. Coccinellidae, ladybird, semiochemical, behaviour, habitat, forage(ing)

\begin{abstract}
Knowledge of semiochemically-mediated behavioural mechanisms of the seven-spot ladybird, Coccinella septempunctata L., is limited but sufficient to encourage further studies in the behavioural ecology of this well known insect. Recent findings on semiochemicals are discussed in relation to the main traits in the ecology of $C$. septempunctata. A putative autumn aggregation pheromone, and effects of allelobiotic plant interactions on habitat preferences of adults are reported. Mechanisms for interaction between an aphid alarm pheromone and plant substances are described, and the kairomonal functions of volatiles from $C$. septempunctata on the parasitoid Dinocampus coccinellae (Schrank) (Hymenoptera: Braconidae) are discussed. Considering the polyphagous diet of C. septempunctata, investigations on the importance of associative learning of chemical cues in foraging behaviour, and further studies on interactions with other third trophic level organisms will provide interesting lines of research.
\end{abstract}

\section{INTRODUCTION}

The seven-spot ladybird, Coccinella septempunctata L. (Coleoptera: Coccinellidae), is a common, easily recognisable insect that has attracted a considerable amount of interest both from professional entomologists and others. It is commercially produced and marketed as a biological aphid control agent. General traits in the life cycle and ecology of coccinellids have recently been elegantly reviewed (Dixon, 2000), but knowledge of the chemical ecology is still rather scant. In this paper, we review some of the chemical ecology of the seven-spot ladybird with special attention to semiochemicals involved in social communication and foraging behaviour. The ecological background to the discussion of semiochemicals can be summarised as follows.

Adults of C. septempunctata migrate to, and hibernate as aggregates in specific sites on prominent landmarks in the landscape such as water towers, rocky ridges etc. (Hodek et al., 1993). The autumn migration can be massive, but the final advance towards the hibernating sites is, to a great extent, dependant on weather conditions, temperatures and rainfall in particular (Klausnitzer, 1989). In Sweden, C. septempunctata normally has only one generation per year. However, given very favourable conditions, a second oviposition may take place, although larvae in this second generation have not been seen to complete their development to adulthood.

During hibernation, the beetles are often attacked by the fungus, Beauveria bassiana (Balsamo) Vuillemin, and the parasitoid, Dinocampus coccinellae (Schrank) (Hymenoptera: Braconidae), which hibernates as an egg in the adult beetle. Depending on foraging conditions, the mortality in East Anglia, UK varies between 9-72\%, with well fed beetles resisting parasitism (Barron \& Wilson, 1998).
The ladybird female feeds on pollen and aphids, and oviposits in the vicinity of aphid colonies. Aphids constitute a staple food for the larvae, but their availability varies greatly both temporally and spatially, so that they are often not continuously available for the entire developmental period, and are sometimes not available throughout the full development of the larvae until the pupal stage. Thus, cannibalism among larvae is a rational solution to emphasize selective advantages for individual cannibals (Dixon, 2000).

\section{AGGREGATION AND SOCIAL COMMUNICATION}

The hibernating aggregations of adult C. septempunctata are usually found at specific sites such as in dry places on top of the mineral soil under leaves close to stones, rocks or dense grass tufts or at the base of bushes. As long as changes in vegetation and ground cover are moderate, these hibernating sites are used year after year. Crevices in walls and buildings are also favourite places, and it has been reported that when hibernation takes place on buildings, it occurs at the very same sites on the house year after year (Hodek et al., 1993; Dixon, 2000). The autumn migration of $C$. septempunctata begins in central Sweden in mid-August and continues as long as temperature permits until late November. The formation of large groups of overwintering adults has led to suggestions that an aggregation pheromone is employed. Considering the specific conditions during the late autumn, such a pheromone should have potent olfactory activity even if the temperatures are low. To be active under longer time it should also be chemically very stable. Indeed, a pheromone fulfilling these expectations was isolated and identified for $C$. septempunctata as 2-isopropyl-3-methoxypyrazine (Fig. 1-1) (Al Abassi et al., 1998). In terms of physical properties, this compound is well suited for its expected functions, as it is not very volatile and is chemi- 
<smiles>CC1CCOc2nccnc21</smiles>

1<smiles>C=CC(=C)CC/C=C(/C)CCC=C(C)C</smiles>

2

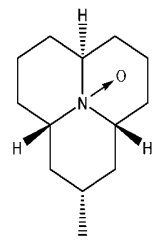

4

5

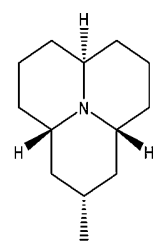

6

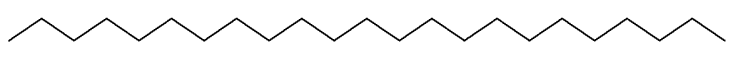

9

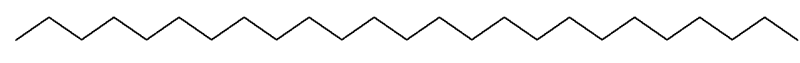

10

Fig. 1. Semiochemicals for the seven-spot ladybird, Coccinella septempunctata, and associated prey, natural enemies and intraguild competitors: 1 - 2-isopropyl-3-methoxypyrazine (pyrazine); 2 - (E)- $\beta$-farnesene; 3 - (-)- $\beta$-caryophyllene; 4 cis-jasmone $((Z)$-jasmone $) ; 5-$ coccinelline; 6 precoccinelline; 7 - myrrhine; 8 - hippodamine; 9 -n-tricosane; 10 - n-pentacosane.

cally stable. Thus, it may function as a messenger substance even if aggregation itself is a slow process that proceeds only on days with favourable temperatures and migratory conditions.

Aggregation is also advantageous to C. septempunctata in allowing the adults to come together for reproduction following emergence in the spring. Little is known about the role of semiochemicals in the reproductive behaviour for C. septempunctata. However, it is likely that such cues are used for mate recognition, as studies have suggested that a sex pheromone is utilised by another species, the two-spot ladybird, Adalia bipunctata (Hemptinne et al., 2000b).

\section{HABITATS}

Efficient use of a broad range of food sources means that identification of favourable habitats can be more profitable than searching for specific food sources. This creates a dynamic balance between investment in localising optimal habitats where food is likely available, and in finding specific preferred food resources.

A simple model of ladybird searching and oviposition behaviour emerged in the 1950s. Adult ladybirds are highly mobile in traversing the landscape, but become less active and produce more eggs as their rate of aphid consumption increases. The net result is that most eggs tend to be laid at sites of high aphid density. Laboratory and field experiments and observations over the past several decades have generally supported this basic model, although the link between ladybird dispersal activity and local aphid density often appears to be relatively weak (Evans, 2003). Thus, there are good reasons to attempt to identify further mechanisms potentially guiding searching behaviour.

The general hypothesis of ladybird searching behaviour implies that adults move in the landscape and remain to feed and oviposit where they find aphids. Considerable attention has been given to the fact that an aphid colony is a very dynamic and ephemeral food source which has a special importance for larval survival (Ferran \& Dixon, 1993). Thus, the foraging behaviour of coccinellid larvae has been extensively studied in an attempt to determine their potential for controlling pest aphids. Poor progress in developing a foraging theory for insect predators, and ladybirds in particular, is a consequence of inadequate attention to the foraging behaviour of the adults (Ferran \& Dixon, 1993) and the cues they use to locate prey patches.

C. septempunctata is a well known aphid predator, but it is polyphagous and also uses botanical food sources such as pollen if available. In line with the hypothesis that habitat search is an important strategy for polyphagous insects, this would mean that both aphid occurrence and plants producing pollen at suitable times would be components in searching strategy mechanisms. Experiments on plant attraction of ladybirds have been done. At least 20 of 73 plant species (mainly agricultural weeds) were highly attractive to coccinellids (Schmid, 1992). C. septempunctata dominated among the eighteen coccinellid species found in this field experiment, and 11 plants had sufficient aphid numbers to permit reproduction. Coccinellid abundance appeared to be most strongly correlated with the percentage ground cover of some weed species (Leather et al., 1999).

Field investigations have also shown a correlation between increased botanical diversity and the frequency of polyphagous predators, and different factors are suggested to contribute to this, including microclimate and increased prey density (Andow, 1991; Vandermeer, 1992). As a general principle, the efficiency of the searching behaviour of a predator would benefit from a mechanism for identifying stressed plants, i.e. plants where the probability of finding herbivores is increased. The most common biotic challenge for an individual plant is sharing available growth resources with other plants. In some systems, this has led to the development of an 
advanced level of plant/plant communication via allelochemicals. Suppression of plant competitors via allelochemicals (allelopathy sensu Molisch, 1937) has been recognised since ancient times. Preparation for competition, by modified development, upon recognition of plant neighbours (allelobiosis sensu Pettersson et al., 2003) is less well known, and its importance in a tritrophic perspective including herbivores and their natural enemies has not been extensively studied. Hypothetically, polyphagous predators possess a general recognition of plants responding to different stress factors. This hypothesis would gain support if it were shown that plant/plant communication via allelochemicals can cause changes in polyphagous predator orientation. Studies of behavioural responses of adults of $C$. septempunctata to barley and two common barley crop weeds contribute to this discussion.

An inventory of $C$. septempunctata in a commercial barley crop with weeds indicates the importance of odour stimuli. Adults were significantly aggregated to patches with Elytrigia repens and Cirsium arvense, although no obvious food resource such as pollen, aphids or other small prey insects were abundant (Ninkovic \& Pettersson, 2003). In olfactometer experiments, adult ladybirds showed no difference in orientation to either of the weeds. However, when barley and one of the two weeds was used as a combined odour source this was preferred compared to barley alone. Barley plants exposed to volatiles from $C$. arvense remained attractive when the weed was taken away, whereas those exposed to E. repens lost their attractiveness. This indicates that the positive effect of the barley/E. repens combination may merely be an effect of mixed volatiles, whereas the barley/C. arvense mixture is likely to represent a more complex mechanism involving allelobiosis.

The general conclusion from these results is that mixed plant stands can have a stronger arresting effect on adult ladybirds than pure stands. Hypothetically, the arresting effect could be a response to complexity of plant volatiles. This would fit well with the E. repens-barley combination. However, the results from the tests of the $C$. arvense-barley combination suggest another possibility. Barley plants exposed to allelobiotic provocation from thistle volatiles become significantly less acceptable to aphids (Glinwood et al., 2004). Thus, the positive ladybird response to $C$. arvense-exposed barley plants could be a response to a plant stress condition which is similar both for plant/plant- and aphid attack released effects. This would be in line with a positive ladybird response to aphid attacked barley plants (Ninkovic et al., 2001).

\section{FOOD}

Predator mobility plays an important role in foraging efficiency and is greatly affected by factors such as plant morphology and plant surface structure. Investigations on the predatory efficiency of C. septempunctata on Acyrthosiphon pisum on leafless mutants of Pisum sativum showed that the effect of predation was reduced by $50 \%$ compared to normal plant types. Ladybirds fal- ling from the plant was claimed to be the main factor (Kareiva \& Sahakian, 1990). Ladybirds use different sets of stimuli for food localisation and it has been suggested that associative learning may play an important role in increasing efficiency (Vet \& Dicke, 1992). However, experimental support for this hypothesis seems to be meagre so far.

When attacked, many aphids release a secretion from the cornicles that contains an alarm pheromone. Nearby aphids respond by pulling out their mouthparts and falling from the leaf to escape (Nault et al., 1973). The main component of the pheromone for many species is the sesquiterpene hydrocarbon (E)- $\beta$-farnesene (Fig. 1-2, EBF). Experimental studies have shown that adult $C$. septempunctata and larval $A$. bipunctata are arrested/attracted to EBF and the odour of crushed aphids respectively (Al Abassi et al., 2000; Hemptinne et al., 2000b). EBF is also a common substance in nature, occurring in several plants. This represents a potential problem since a rigid positive response to it may cause the ladybird to stay longer in environments which are less favourable. However, it has been demonstrated that the response of C. septempunctata is modified by another common plant substance, (-)- $\beta$-caryophyllene (Fig. 1-3) (Al Abassi et al., 2000). As long as a specific ratio is maintained between these two substances, no behavioural response is released. This is the case when a walking ladybird passes an undisturbed aphid colony. However, if one of the individuals in the colony responds to the threat of a predator and then releases the alarm pheromone, this substance ratio is disturbed, and the behaviour of the ladybird is changed to aggressive predation.

Several experimental studies have shown how natural enemies respond to volatiles from plants attacked by herbivores. Infested plants represent habitats where prey is likely to be found. Thus, it is not surprising that adult ladybirds are attracted to the odour of aphid-infested plants. In a series of olfactometer experiments, it was found that adult $C$. septempunctata are able to distinguish between aphid-infested and intact plants using olfactory cues (Ninkovic et al., 2001). Previous studies have shown that dense aphid colonies on cereal plants release a set of density related volatile substances (DRS) (Quiroz et al., 1997). Some of these substances are suggested to act as aphid colony density activators. These substances may potentially be used by ladybirds as lead substances to identify plant individuals that are under herbivore attack and thus offer a food resource. Olfactometer experiments with adults of $C$. septempunctata and aphid density related substances (DRS) show that these substances release an arresting response (Ninkovic et al., unpubl.). The nature of the specific volatile blend is so far not known. However, it can be hypothesized that there are fairly non-specific changes in the volatile profile of plants under different kinds of stress.

cis-Jasmone, or (Z)-jasmone, (Fig. 1-4) is a well known component of plant volatile blends, and its release can be induced by damage, for example during insect herbivory. Using the olfactory system of the lettuce aphid to investi- 
gate volatiles from plants avoided by this insect, (Z)-jasmone was found to be electrophysiologically active and also to be repellent in laboratory choice tests (Birkett et al., 2000). In field studies, repellency from traps was demonstrated for the damson-hop aphid, and cereal aphids numbers were reduced in plots of winter wheat treated with ( $Z$ )-jasmone. In contrast, laboratory and wind tunnel tests with $(Z)$-jasmone and $C$. septempunctata adults demonstrated attraction. When applied in the vapour phase to intact bean plants, $(Z)$-jasmone induced the production of volatile compounds, including the monoterpene $(E)$-ocimene, which is an attractant for the aphid parasitoid, Aphidius ervi.

There is evidence that ladybirds also affect aphid development not only by predation. Aphids may increase the production of winged offspring when exposed to volatiles from footprints of coccinellid larvae (Dixon \& Agarwala, 1999). This could be an effect of physical contacts and interrupted aphid feeding, but could also be caused by repellent semiochemicals that increase the mobility of aphid individuals. This would be in line with demonstrated increased aphid mobility released by chemical cues related to aphid population density (Quiroz et al., 1997).

\section{ENEMIES AND COMPETITORS}

The formation of overwintering aggregations by ladybirds is an invitation to invertebrate and vertebrate predation if defensive mechanisms are not present (Majerus \& Majerus, 1997). However, the brilliant red or yellow colouration, with contrasting black spots and a welldeveloped chemical defence system involving reflex bleeding make ladybirds a classic example of successful aposematism (Holloway et al., 1991). For C. septempunctata, the secreted fluid, which is emitted at the tibiofemoral joints, contains highly toxic alkaloids. Coccinelline (Fig. 1-5), the $N$-oxide of the free base precoccinelline (Fig. 1-6), has extremely high mammalian toxicity (Marples, 1993b), and both compounds are released along with the volatile pyrazine (Fig. 1-1), which thus serves a dual role in $C$. septempunctata chemical ecology as an enemy repellent and aggregation pheromone (Al Abassi et al., 1998). The amount of reflex fluid emitted by ladybirds in response to an attack can be very high (up to $20 \%$ of fresh body weight), and the weight of the alkaloid can amount to several percent of the weight of the fluid (Holloway et al., 1993). The potential aposematic cues present in the multiple-component defence secretion of $C$. septempunctata have been investigated in feeding experiments with Japanese quail, Coturnix coturnix japonicus ( Marples et al., 1994). It was found that colour pattern was the most effective single deterrent, but the interaction between colour and taste was also important. The birds detected the insect's smell, but rarely used it as a cue to toxicity. No single element was sufficient to maintain avoidance comparable to the whole insect.

In studies on ladybird-ant interactions, it has been suggested that alkaloids may also be part of an aposematic relationship between Lasius niger and C. septempunctata, thereby protecting the ladybird from attacks by the ants and increasing its chances of prey consumption (Marples, 1993a). This form of protection seems to be better developed for C. septempunctata than for A. bipunctata, and is in agreement with the observation that $C$. septempunctata appears to use the trail pheromones of Formica polyctena (Forst.) in foraging (Bhaktar, 1982). The specific relationship between ants and C. septempunctata, compared to that between ants and Harmonia quadripunctata, has also been observed for ant-attended aphid colonies on Scots pine, Pinus sylvestris (Slogett \& Majerus, 2000). It has been suggested that ant attendance prolongs the survival of aphid colonies, thus stabilising the food supply for the ladybirds.

Adult ladybirds are attacked by the parasitic wasp $D$. coccinellae. The parasitoids oviposit during late summer, but the eggs rest in the body cavity until the following spring, and only develop when the host leaves the hibernating site and starts to feed. The oviposition process is very rapid and seems to be initiated by a specific set of stimuli. An exciting discovery was that volatile semiochemicals play a key role in location of adult C. septempunctata. In laboratory experiments, it was demonstrated that the free base precoccinelline (Fig. 1-6) is attractive, and is highly active at the electrophysiological level (Al Abassi et al., 2001). Other naturally occurring ladybird alkaloids with similar structures, i.e. myrrhine (Fig. 1-7), from the eighteen spot ladybird, Myrrha octodecimguttata, and hippodamine (Fig. 1-8), from the convergent ladybird, Hippodamia convergens, were also found to have significant biological activity on the parasitoid. However, it remains to be seen to what extent stimuli other than olfactory cues contribute to orientation of the wasp towards its host under natural field conditions.

Aphids are attacked by parasitoids such as Aphidius ervi, which oviposit in aphid individuals, and the developing parasitoid larva consumes the aphid from inside. As aphids also constitute a preferred staple food for C. septempunctata, there is an obvious risk for the parasitoid offspring if the female oviposits in aphids that are eaten by ladybirds i.e. intraguild predation (IGP). Recently, elegant studies have shown that in order to avoid IGP, female $A$. ervi detect semiochemicals found in C. septempunctata adult and larval footprints recently deposited on leaf surfaces, thereby avoiding those aphid colonies under attack from ladybirds, i.e. intraguild avoidance. The major components in footprint trails responsible for the avoidance were identified as n-tricosane (Fig. 1-9) and n-pentacosane (Fig. 1-10) (Nakashima et al., 2004). A similar mechanism has been described for the relationship between the aphid parasitoid, A. colemani and C. septempunctata, Harmonia axyridis and Propylea japonica, where the number of eggs deposited in colonies with coccinellid larvae was reduced in the presence of semiochemicals from the larval tracks of C. septempunctata. (Takizawa et al., 2000). Semiochemicals also appear to play a role in intraguild interactions between $C$. septempunctata and other aphid natural enemies. The goldeneye lacewing, Chrysopa oculata, utilises an oviposition- 
deterring pheromone (ODP) which also acts as an oviposition-deterring allomone for C. septempunctata (Rưžička, 1997). Adaptation to the shared use of aphid colonies as a dynamic food source between syrphids and coccinellids has been suggested, although all behavioural aspects have not been clarified (Hemptinne et al., 1993).

In situations where food sources are scarce, egg and larval cannibalism by adult and late-instar ladybird larvae is commonplace. From an ecological point of view, this is an efficient way to use available resources at a specific feeding site. It also fits well with the fact that the larval mobility over longer distances for foraging is limited i.e. the resources should be used optimally where the adults have placed the eggs (Dixon, 2000). Detection of conspecific adults by egg-laying adults would be advantageous for avoidance of egg cannibalism. The role of an ODP for C. septempunctata has been defined (Růžička, 1997), and an ODP has been reported for $A$. bipunctata. Thus, gravid females can utilise semiochemicals present in conspecific larval tracks to avoid oviposition where larvae are already present (Hemptinne et al., 2001). The specificity of the ODP is illustrated by the fact that female $A$. bipunctata do not avoid tracks deposited by larvae of two other species, A. decempunctata and C. septempunctata (Hemptinne \& Dixon, 2000). Egg surface chemicals have been suggested as semiochemicals for avoidance of intraguild (egg) predation between $C$. septempunctata and $A$. bipunctata (Hemptinne et al., 2001). Where the chemical nature of $A$. bipunctata semiochemicals has been investigated for reproduction, oviposition deterrence and intraguild avoidance, similar alkanes have been identified in each case, indicating that ladybirds exploit their natural product chemistry with parsimonious versatility, similar to that described above for the pyrazine (Fig. 1-1) which is used in chemical defence and aggregation (Hemptinne \& Dixon, 2000). Intraguild interactions between $H$. axyridis and $P$. japonica are mediated by odour substances from faeces (Agarwala et al., 2003). This mechanism is an interspecific complement to the intraspecific communication and reduces competition between these two coccinellid species.

\section{CONCLUDING REMARKS}

The literature on the ecology of $C$. septempunctata is considerable, and the overall population ecology has been well condensed and presented in reviews (see Hodek et al., 1993; Hodek \& Honěk, 1996; Dixon, 2000; Majerus, 1994). However, the role of semiochemical cues in modifying ladybird behaviour is less well studied, although $C$. septempunctata has sometimes been used as a model for polyphagous predators (Vet \& Dicke, 1992). This review does not cover the complete life history, but rather summarizes recent findings on how semiochemicals may contribute to different parts of life history. Social interaction is linked to chemistry which is connected to the aposematic survival strategy. The putative autumn aggregation pheromone is a very potent component of chemical defence that is linked to the aposematic visual appearance. Another defence component is used as a kai- romone by the specialised parasitoid $D$. coccinellae in its host recognition during oviposition.

Habitat choice and foraging behaviour have attracted considerable interest in studies of the ecology and life history of $C$. septempunctata. Since it is a polyphagous species, a capacity for learning has been hypothesised (Vet \& Dicke, 1992). This would be expected as an adaptation for more efficient foraging behaviour and, if manifested as a decrease in searching area, several different cues could be employed. If prey represents a patchy resource distribution, feeding makes individuals spend more time in food patches. Learning sensu stricto (Papaj, 1993) confers the capacity to mobilise the use of a certain stimulus or groups of stimuli. Two examples of habitat/food related semiochemical stimuli are given above. One is related to aphid attacked plants and the other to monoculture versus mixed plant species. Until more is known about the chemical substances composing the cues, at least two explanations are available. One is that aphidattacked plants and allelobiotically-promoted plants express stress in a similar way with regards to emission of volatiles. The other is that there is an adaptive value for the ladybird in choosing habitats with a higher degree of botanical diversity. Present investigations do not indicate which of these options is the more likely, however, they do add new semiochemical dimensions to the predicted importance of botanical diversity on the two next trophic levels, i.e. herbivores and their natural enemies.

\section{REFERENCES}

Al Abassi S., Birkett M.A., Pettersson J., Pickett J.A., WadHAMS L.J. \& Woodcock C.M. 1998: Ladybird beetle odour identified and found to be responsible for attraction between adults. Cell. Mol. Life Sci. 54: 876-879.

Al Abassi S., Birkett M.A., Pettersson J., Pickett J.A., WadHams L.J. \& Woodcock C.M. 2000: Response of the sevenspot ladybird to an aphid alarm pheromone and an alarm pheromone inhibitor is mediated by paired olfactory cells. $J$. Chem. Ecol. 26: 1765-1771.

Al Abassi S., Birkett M.A., Pettersson J., Pickett J.A., WadHAMs L.J. \& WoODCock C.M. 2001: Response of the ladybird parasitoid Dinocampus coccinellae to toxic alkaloids from the seven-spot ladybird, Coccinella septempunctata. J. Chem. Ecol. 27: 33-43.

Agarwala B.K., Yasuda H., KaJita Y. 2003: Effect of conspecific and heterospecific feces on foraging and oviposition of two predatory ladybirds: Role of fecal cues in predator avoidance. J. Chem. Ecol. 29: 357-376

ANDow D.A. 1991: Vegetational diversity and arthropod population responses. Annu. Rev. Entomol. 36: 561-586.

BHATKAR A.P. 1982: Orientation and defense of ladybeetles (Coleoptera, Coccinellidae) following ant trail in search of aphids. Folia Entomol. Mex. 53: 75-85.

BARRon A. \& Wilson K. 1998: Overwintering survival in the seven spot ladybird, Coccinella septempunctata (Coleoptera: Coccinellidae). Eur. J. Entomol. 95: 639-642.

Birkett M.A., Campbell C.A.M., Chamberlain K., Guerrieri E., Hick A.J., Martin J.L., Matthes M., Napier J.A., Pettersson J., Pickett J.A., Poppy G.M., Pow E.M., Pye B.J., Smart L.E., Wadhams G.H., Wadhams L.J. \& Woodcock C.M. 2000: New roles for cis-jasmone as an insect semio- 
chemical and in plant defense. Proc. Nat. Acad. Sci. USA 97: 9329-9334.

Dixon A.F.G. 2000: Insect Predator-Prey Dynamics: Ladybird Beetles and Biological Control. Cambridge University Press, Cambridge, UK, $257 \mathrm{pp}$.

Dixon A.F.G. \& Agarwala B.K. 1999: Ladybird-induced lifehistory changes in aphids. Proc. R. Soc. Biol. Sci. (B) 266: $1549-1553$

Evans E.W. 2003: Searching and reproductive behaviour of female aphidophagous ladybirds (Coleoptera: Coccinellidae): A review. Eur. J. Entomol. 100: 1-10.

FERran A. \& Dixon A.F.G. 1993: Foraging behaviour of ladybird larvae (Coleoptera: Coccinellidae). Eur. J. Entomol. 90: 383-402.

Glinwood R., Ninkovic V., Ahmed E. \& Pettersson J. 2004: Barley exposed to aerial allelopathy from thistles (Cirsium spp.) becomes less acceptable to aphids. Ecol. Entomol. 29: 188-195.

Hemptinne J.L. \& Dixon A.F.G. 2000: Defence, oviposition and sex: Semiochemical parsimony in two species of ladybird beetles (Coleoptera, Coccinellidae)? A short review. Eur. J. Entomol. 97: 443-447.

Hemptinne J.L., Dixon A.F.G., Doucet J.L. \& Petersen J.E. 1993: Optimal foraging by hoverflies (Diptera: Syrphidae) and ladybirds (Coleoptera: Coccinellidae): Mechanisms. Eur. J. Entomol. 90: 451-455.

Hemptinne J.L., Lognay G., Gauthier C. \& Dixon A.F.G. 2000a: Role of surface chemical signals in egg cannibalism and intraguild predation in ladybirds (Coleoptera: Coccinellidae). Chemoecology 10: 123-128.

Hemptinne J.L., Gaudin M., Dixon A.F.G. \& Lognay G. 2000b: Social feeding in ladybird beetles: Adaptive significance and mechanism. Chemoecology 10: 149-152.

Hemptinne J.L., Lognay G., Doumbia M. \& Dixon A.F.G. 2001: Chemical nature and persistence of the oviposition deterring pheromone in the tracks of the larvae of the two spot ladybird, Adalia bipunctata (Coleoptera, Coccinellidae). Chemoecology 11: 43-47.

Hodek I. \& HonĚK A. 1996: Ecology of Coccinellidae. Kluwer, Dordrecht, $464 \mathrm{pp}$.

Hodek I., IPERTI G. \& HodKovÁ M. 1993: Long-distance flights in Coccinellidae (Coleoptera). Eur. J. Entomol. 90: 403-414.

Holloway G.J., De Jong P.W., Brakefield P.M. \& De Vose H. 1991: Chemical defense in ladybird beetles (Coccinellidae). I. Distribution of coccinelline and individual variation in defence in 7-spot ladybirds (Coccinella septempunctata). Chemoecology 2: 7-14.

Holloway G.J., De Jong P.W. \& Ottenheim M. 1993: The genetics and cost of chemical defense in the two-spot ladybird (Adalia bipunctata L.). Evolution 47: 1229-1239.

Kareiva P. \& Sahakian R. 1990: Tritrophic effects of a simple architectural mutation in pea plants. Nature 345: 433-434.

Klausnitzer B. 1989: Aggregations of ladybirds on the Baltic coast (Col., Coccinellidae). Entomol. Nachr. Ber. 33: 189-195.

Leather S.R., Cooke R.C.A., Fellowes M.D.E. \& Rombe R. 1999: Distribution and abundance of ladybirds (Coleoptera: Coccinellidae) in non-crop habitats. Eur. J. Entomol. 96: 23-27.

Majerus M. 1994: Ladybirds. The New Naturalist Series 81. Harper \& Collins, London, 368 pp.
Majerus M.E.N. \& Majerus T.M.O. 1997: Predation of ladybirds by birds in the wild. Entomol. Mon. Mag. 133: 55-61.

MARPLES N.M. 1993a: Is the alkaloid in 2-spot ladybirds (Adalia bipunctata) a defence against ant predation? Chemoecology 4: 29-32.

Marples N.M. 1993b: Toxicity assays of ladybirds using natural predators. Chemoecology 4: 33-28.

Marples N.M., Van Veelen W. \& Brakefield P.M. 1994: The relative importance of colour, taste and smell in the protection of an aposematic insect Coccinella septempunctata. Anim. Behav. 48: 967-974.

Molisch H. 1937: Der Einfluss einer Pflanze auf die andere: Allelopathie. Gustav Fischer, Jena, 106 pp.

Nakashima Y., Birkett M.A., Pye B.J., Pickett J.A. \& Powell W. 2004: The role of semiochemicals in the avoidance of the seven-spot ladybird, Coccinella septempunctata by the aphid parasitoid, Aphidius ervi. J. Chem. Ecol. 30: 1103-1116.

Nault L.R., Edwards L.J. \& Styer W.E. 1973: Aphid alarm pheromones: secretion and reception. Environ. Entomol. 2: 101-105.

Ninkovic V. \& Pettersson J. 2003: Plant/plant communication supports searching behaviour of the seven-spotted ladybird, Coccinella septempunctata (L.)? Oikos 100: 65-70.

Ninkovic V., Al Abassi S. \& Pettersson J. 2001: The influence of aphid - induced plant volatiles from barley on the searching behaviour of the seven spot ladybird, Coccinella septempunctata. Biol. Contr. 21: 191-195.

PAPAJ D.R. 1993: Afterword: Learning, Adaptation and the lessons of O. In Papaj D.R. \& Lewis A.C. (eds): Insect Learning: Ecological and Evolutionary Perspectives. Chapman \& Hall, London, pp. 374-386.

Pettersson J., Ninkovic V. \& Glinwood R. 2003: Plant activation of barley by intercropped conspecifics and weeds: allelobiosis. The BCPC International Congress - Crops Science \& Technology, pp. 1135-1144.

Quiroz A., Pettersson J., Pickett J.A., Wadhams L. \& NieMEYER H.M. 1997: Key compounds in a spacing pheromone in the bird cherry - oat aphid, Rhopalosiphum padi (L.) (Hemiptera, Aphididae). J. Chem. Ecol. 23: 2599-2607.

RỦŽIČKA Z. 1997: Recognition of oviposition-deterring allomones by aphidophagous predators (Neuroptera: Chrysopidae, Coleoptera: Coccinellidae). Eur. J. Entomol. 94: 431-434.

ScHMID A. 1992: Investigations on the attractiveness of agricultural weeds to aphidophagous ladybirds (Coleoptera, Coccinellidae). Agrarökologie 5: 122 pp.

Sloggett J.J. \& Majerus M.E.N. 2000: Aphid-mediated coexistence of ladybirds (Coleoptera: Coccinellidae) and the wood ant Formica rufa: Seasonal effects, interspecific variability and the evolution of a coccinellid myrmecophile. Oikos 89: 345-359.

Takizawa T., Yasuda H. \& Agarwala B.K. 2000: Effect of three species of predatory ladybirds on oviposition of aphid parasitoids. Entomol. Sci. 3: 465-469.

VANDERMEER J. 1992: The Ecology of Intercropping. Cambridge University Press, Cambridge, UK, 249 pp.

Vet L.E.M. \& Dicke M. 1992: Ecology of infochemical use by natural enemies in a tritrophic context. Annu. Rev. Entomol. 37: 141-172.

Received September 10, 2004; revised March 7, 2005; accepted March 15, 2005 